\section{THE CHILD IN HEALTH AND DISEASE}

Edited by C. G. GruleE, M.D., and R. C. Eley, M.D. 2nd Edition. Pp. xvi $+1,255$, with 304 illustrations. London: Ballière, Tindall and Cox. 1952. II 4 S.

\section{FANCONI AND WALLGREN'S TEXTBOOK OF PAEDIATRICS}

Edited by W. R. F. Collis, M.A., M.D., F.R.C.P., F.R.C.P.I., D.P.H. Pp. $x x+1,104$, with 440 illustrations. London: William Heinemann. 1952. $£ 77 \mathrm{~s}$.

General textbooks of paediatrics tend to fall into two groups. There is the one-man work, based largely on personal experience, containing a simple account of normal development and descriptions of the common problems and diseases of childhood and intended to be read through by the undergraduate. In the second group is the larger comprehensive textbook with many contributors, which no one, however greedy for erudition, would be prepared to read from cover to cover, but which serves a useful purpose as a work of reference in enabling one to obtain more complete information about any paediatric subject. The chapters of such a book should be balanced and up-to-date reviews of their subjects and should be followed by references to important original papers.

Such a work is the second edition of the American textbook by Grulee and Eley and written by 87 contributors, and in scope it may be compared to the English 'Garrod, Batten and 'Thursfield' or the American ' Mitchell-Nelson.' The Continental textbook 'Fanconi and Wallgren,' on the other hand, seems to belong to neither group. In length it is about two-thirds that of the American book and the subject matter tends to be too unbalanced for a student and yet too incomplete as a work of reference. Moreover, there are comparatively few references to original papers.

The arrangement of the subject matter in ' Grulee and Eley' is unusual. Due, no doubt, to the special interests of Dr. Eley, great emphasis is laid on infectious disease. Streptococcal bacteraemia, tonsillitis, otitis media, mastoiditis, sinusitis, peritonitis, vaginitis, osteomyelitis, etc., are all considered in the chapter on 'Streptococcosis' instead of being found, as is more con- ventional, in chapters devoted to diseases of each system. In some ways this is confusing, as the acute pyogenic meningitides, for instance, are considered in no less than six different parts of the book, but on the whole the reviewer feels that this method of presentation has much to commend it.

There is a certain lack of balance between chapters; perhaps the most obvious example is that 19 pages are devoted to pancreatic fibrosis, whilst coeliac disease is accorded no recognition. But some inequality of treatment is inevitable in such a textbook. Amongst the new chapters is one already mentioned-on pancreatic fribosis-and one on erythroblastosis foetalis by experts in these fields from the Boston Children's Hospital. Special mention must also be made of the chapter 'Diseases of the Nervous System' by Dr. D. Buchanan, which is, in the reviewer's opinion, the best to be found in any textbook of children's diseases.

In both books there are indications of expansionist activities amongst paediatricians in the shape of chapters on adolescence and information on this neglected subject is welcome.

The Continental textbook is an English translation of the 'Lehrbuch der Padiatrie' by Fanconi and Wallgren. This edition has been prepared by Dr. Collis of Dublin, who is also a contributor. The translation has been made by Dr. E. Kawerau who, in a disarming introductory note, explains some of the difficulties and problems he has had to face. In general these have been remarkably well overcome and the style is easy to read and none the worse for being unfamiliar. There are, however, passages such as "From the age of four months, a healthy child begins to "'make strange ",' which means little more even in their contexts and these should surely have been altered in the editing.

The authors are 19 distinguished paediatricians, mostly from Sweden and Switzerland, but also from seven other European countries.

Although full of useful and interesting information the book suffers from unevenness of presentation. The descriptions of common and important subjects are frequently too brief, whilst much space is devoted to highly specialized aspects of paediatrics. Thus the chapter on the pneumonias is only onesixth the length of that in 'Grulee and Eley,' whilst in the section on heart disease only four lines are allotted to atrial septal defect, although much space is occupied by diagrams of electrocardio- 